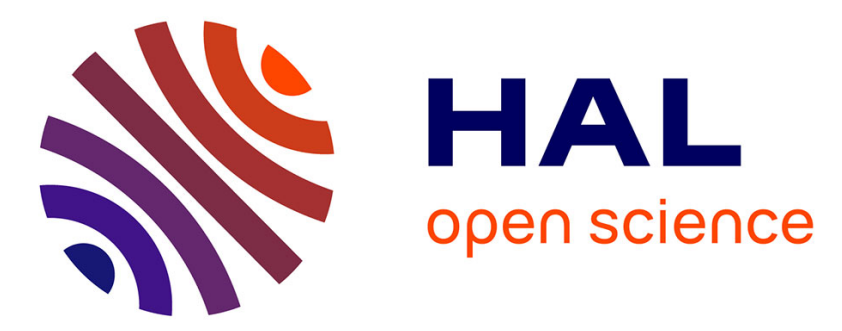

\title{
Evaluation of ellipsometric porosimetry for in-line characterization of ultra low- $\kappa$ dielectrics
}

C. Licitra, F. Bertin, Maxime Darnon, T. Chevolleau, C. Guedj, S. Cetre, H. Fontaine, A. Zenasni, L.L. Chapelon

\section{- To cite this version:}

C. Licitra, F. Bertin, Maxime Darnon, T. Chevolleau, C. Guedj, et al.. Evaluation of ellipsometric porosimetry for in-line characterization of ultra low- $\kappa$ dielectrics. physica status solidi (c), 2008, 5 (5), pp.1278-1282. 10.1002/pssc.200777776 . hal-00387517

\section{HAL Id: hal-00387517 https://hal.science/hal-00387517}

Submitted on 22 Mar 2021

HAL is a multi-disciplinary open access archive for the deposit and dissemination of scientific research documents, whether they are published or not. The documents may come from teaching and research institutions in France or abroad, or from public or private research centers.
L'archive ouverte pluridisciplinaire $\mathbf{H A L}$, est destinée au dépôt et à la diffusion de documents scientifiques de niveau recherche, publiés ou non, émanant des établissements d'enseignement et de recherche français ou étrangers, des laboratoires publics ou privés. 


\title{
Evaluation of ellipsometric porosimetry for in-line characterization of ultra low-א dielectrics
}

\author{
C. Licitra*1, F. Bertin', M. Darnon ${ }^{2}$, T. Chevolleau' ${ }^{2}$, C. Guedj', S. Cetre', H. Fontaine', A. Zenasni', \\ and L. L. Chapelon ${ }^{3}$
}

${ }^{1}$ CEA LETI - MINATEC, 17 rue des Martyrs, 38054 Grenoble, France
${ }^{2}$ LTM/CNRS (CEA LETI - MINATEC), 17 rue des Martyrs, 38054 Grenoble, France
${ }^{3}$ STMicroelectronics, 850 rue Jean Monnet, 38926 Crolles, France

* Corresponding author: e-mail christophe.licitra@cea.fr, Phone: +33 (0)438785641, Fax: +33 (0)438785273

\begin{abstract}
Ellipsometric porosimetry (EP) has recently appeared to be a suitable non-destructive technique for the characterization of porous ultra low- $\kappa$ (ULK) dielectrics. The analysis of ellipsometric spectra of a film during adsorption and desorption cycles of an adsorptive, allows the determination of its open pore fraction, pore size distribution, refractive index and
\end{abstract}

1 Introduction Complementary metal oxide semiconductor (CMOS) down scaling requires new materials for advanced interconnects to reduce resistancecapacitance delay. For the sub-65 nm technology nodes, one challenging solution is to introduce porous ultra low- $\kappa$ (ULK) dielectrics with low permittivity $(\kappa<2.5)$, as fixed by the International Technology Roadmap for Semiconductors [1]. However, the pore structure affects the material properties (mechanical strength, species diffusion through the pore network, moisture uptake...). As these films are being introduced in integrated circuits, new characterization techniques are needed to assess their properties Several techniques have been recently developed to address this challenge such as Positron Annihilation Lifetime Spectroscopy (PALS) [2, 3], Small Angle X-Ray Scattering (SAXS) [4] or Ellipsometric Porosimetry (EP) [5, 6].

Based on spectroscopic ellipsometry measurements, EP consists in the calculation of the optical index of the porous material while an adsorptive is filling the pores. Thus, several parameters of interest can be deduced from the measurements such as the mean pore radius, the pore size distribution and the overall open pore fraction [7]. While thickness. Several issues are encountered when integrating low- $\kappa$ materials as inter-metal dielectrics (IMD) in the CMOS architecture such as the deposition monitoring, the pore sealing efficiency and the process induced damages. In this study we focus on the capabilities of EP to characterize ULK materials and their integration processes. ellipsometry is a common technique performed in microelectronics clean rooms, EP is still under evaluation to become an in-line characterization method. In this study we focus on the assessment of an EP equipment, installed in a clean room environment, and its ability to suit the characterization needs of 200 and $300 \mathrm{~mm}$ ultra low- $\kappa$ process integration schemes. Several key points are discussed especially the questions of sample preparation, sacrificial phase extraction monitoring, impact of plasma etching and pore sealing treatments on blanket or patterned wafers.

\section{Experimental}

2.1 Porous thin films Two kinds of mesoporous thin films were obtained on $200 \mathrm{~mm}$ and $300 \mathrm{~mm}$ silicon wafers. The first type is an amorphous $a$-SiOC:H (organo silicate glass or carbon doped silicon dielectrics) deposited by Plasma Enhanced Chemical Vapor Deposition (PECVD). This $a$-SiOC:H is a silicon-oxygen backbone containing methyl groups grafted on a silicon oxide-based matrix. To decrease the $\kappa$-value to 2.5 , nanometre scale pores are introduced into the film. The porogen (polymeric pore generator) approach consists in removing the sacrifi- 
cial organic part of a dual phase material by an appropriate curing. This in situ post treatment is performed by e-beam or thermal assisted UV curing $\left(400{ }^{\circ} \mathrm{C}\right)$ inducing film shrinkage and enabling to achieve a porosity of $29 \%$ with a mean pore radius around $1 \mathrm{~nm}$. UV curing also enhances the mechanical performances of the film, strengthening the Si-O-Si matrix by cross-linking [8].

The second type of $a-\mathrm{SiOC}: \mathrm{H}$ is obtained by spin-on deposition (Zirkon V7 from Rohm and Haas Electronic Materials). After a $250{ }^{\circ} \mathrm{C}$ stabilization anneal, the sacrificial organic part is removed via a $450{ }^{\circ} \mathrm{C}$ anneal under a controlled $\mathrm{N}_{2} / \mathrm{H}_{2}$ atmosphere. This material has a $\kappa$ value of 2.2 and an interconnected mesoporosity of $45 \%$.

We also performed measurements on mesostructured $\mathrm{TiO}_{2}$ stable films with a porosity of $34 \%$ and a mean pore radius of $3.5 \mathrm{~nm}$. These films were restored before each measurement with a 5 min ethanol wet cleaning followed by a $300{ }^{\circ} \mathrm{C}$ anneal during $5 \mathrm{~min}$.

2.2 Equipment Measurements were performed in the visible range on an EP12 ellipsometric porosimeter from SOPRA. It consists in a rotating polarizer spectroscopic ellipsometer coupled with a vacuum chamber which is operated at a pressure ranging from $10^{-3}$ torr to the saturation vapor pressure $\left(P_{s}\right)$ of the adsorptive. Three solvents were used as adsorptive: toluene $\left(P_{s}=25\right.$ torr at room temperature, refractive index at $\left.633 \mathrm{~nm} n_{t o l}=1.492\right)$, isopropyl alcohol $\left(P_{s}=38\right.$ torr, $\left.n_{I P A}=1.377\right)$ and methanol $\left(P_{s}=115\right.$ torr, $\left.n_{m e t}=1.329\right)$. Ellipsometric spectra were recorded simultaneously between 1.55 and $4.13 \mathrm{eV}$ with a CCD detector and the angle of incidence was set at $60.15^{\circ}$.

2.3 Calculation Thickness and refractive index of the ULK layers were calculated from the ellipsometric data as a function of the relative pressure $\left(P_{r e l}=P / P_{s}\right.$, with $P$ the chamber pressure) using a Cauchy law in adjunction with a Lorentz oscillator to take into account the absorption band in the ultraviolet region. On the basis of the LorentzLorenz effective medium approximation, the fraction of solvent adsorbed in the pores is calculated at each relative pressure with equation (1).

$$
\begin{aligned}
& \frac{n^{2}\left(P_{\text {rel }}\right)-1}{n^{2}\left(P_{\text {rel }}\right)+2}=\left(1-V_{\text {tot }}\right) \frac{n_{\text {mat }}^{2}-1}{n_{\text {mat }}^{2}+2}+V_{\text {closed }} \frac{n_{\text {vac }}^{2}-1}{n_{\text {vac }}^{2}+2} \\
& +V_{\text {openvac }} \frac{n_{\text {vac }}^{2}-1}{n_{\text {vac }}^{2}+2}+V_{\text {opensol }} \frac{n_{\text {sol }}^{2}-1}{n_{\text {sol }}^{2}+2},
\end{aligned}
$$

where $n\left(P_{\text {rel }}\right), n_{\text {mat }}, n_{\text {vac }}$ and $n_{\text {sol }}$ are respectively the refractive indices of the layer at $P_{r e l}$, the matrix (ULK without pores), the vacuum and the solvent and where $V_{\text {tot }}, V_{\text {closed }}$, $V_{\text {openvac }}$ and $V_{\text {opensol }}$ are respectively the volume fractions of all pores, the closed pores, the open pores that are not filled and the open pores that are filled with solvent.

Since $n_{v a c}=1$ and after measuring the initial refractive index $n_{i}$ of the layer when no pores are filled, one can simplify equation (1) in equation (2) to find the open pore fraction filled with solvent at each relative pressure, without knowing the refractive index of the matrix.

$$
V_{\text {opensol }}\left(P_{r e l}\right)=\frac{\frac{n^{2}\left(P_{r e l}\right)-1}{n^{2}\left(P_{r e l}\right)+2}-\frac{n_{i}^{2}-1}{n_{i}^{2}+2}}{\frac{n_{\text {sol }}^{2}-1}{n_{\text {sol }}^{2}+2}} .
$$

The overall open porosity of the layer is then given by $V_{\text {opensol }}$ when the relative pressure is equal to 1 (all pores filled with solvent). Unfortunately the closed porosity is not accessible unless one knows the refractive index of the matrix. This can be obtained by other techniques such as infrared ellipsometry [9]. The pore radius of mesopores (diameter $>2 \mathrm{~nm}$ ) can be calculated using the Kelvin equation of capillary condensation [10]:

$$
r_{k}=\frac{2 \gamma V_{L}}{R T \ln \left(P / P_{S}\right)},
$$

where $\mathrm{V}_{\mathrm{L}}$ is the molar volume of the solvent (liquid), $\gamma$ the surface tension between the liquid and gas phases, $R$ the universal gas constant and $T$ the absolute temperature. Thus the pore radius $r_{P}$ is given by equation (4) where $t$ is the thickness of the solvent layer condensed on the pore walls before capillary condensation occurs.

$$
r_{P}=r_{k}+t \text {. }
$$

Finally the pore size distribution (PSD) of the layer is deduced from the variations of its refractive index (or its adsorbed solvent volume fraction) versus the pore radius [7]: $d n / d r_{P}$ or $d V_{\text {opensol }} / d r_{P}$.

3 Results and discussion Preliminary tests were carried out to ensure that EP has a good repeatability. $\mathrm{TiO}_{2}$ films deposited on silicon were chosen for their very good stability and the possibility to restore them with a cleaning process. Toluene volumes obtained during four months are presented in Fig. 1. We achieved an open porosity of 33.9 $\pm 0.7 \%$, a refractive index of $1.895 \pm 0.01$ and a mean pore radius of $3.5 \pm 0.2 \mathrm{~nm}$.

Repeatability tests were also performed on ULK materials with toluene. Forty measurements were done with series of ten consecutive measurements between the load/unload procedure (Fig. 2). 


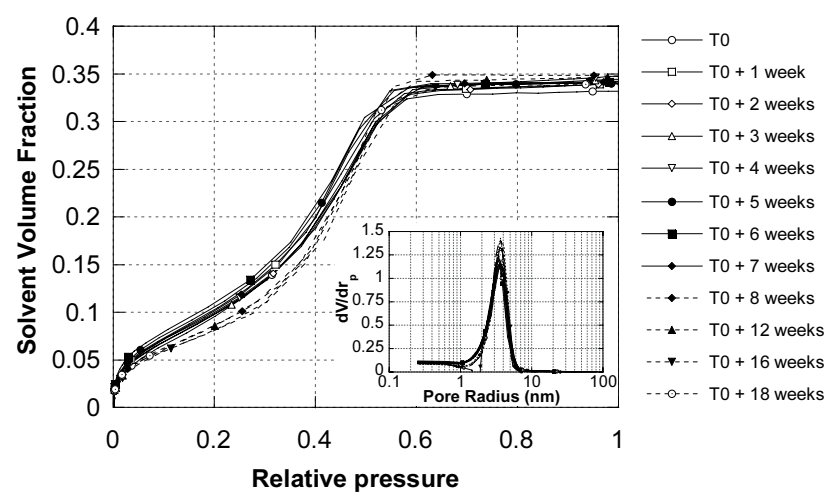

Figure 1 Solvent volume and PSD repeatability of $\mathrm{TiO}_{2}$.

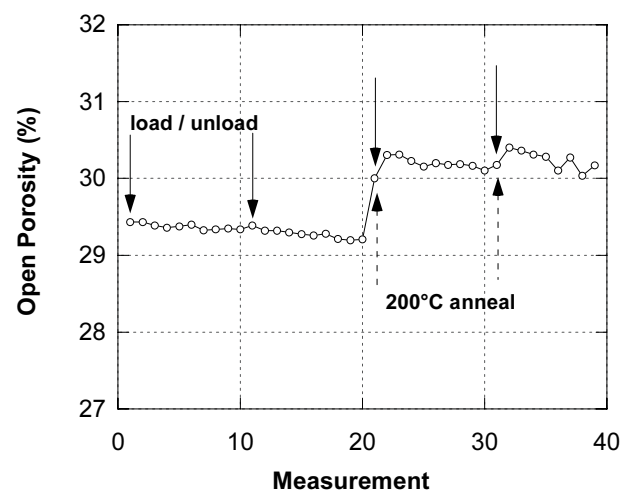

Figure 2 Porosity repeatability of a PECVD ULK.

We obtained a very good repeatability between consecutive measurements but also after unloading and loading the wafer. The major effect comes off when the sample is annealed $\left(5 \mathrm{~min}, 200^{\circ} \mathrm{C}\right)$. The open porosity increases after the two anneals. The thermal process might have desorbed some contaminants or water molecules trapped in the layer. Thus, depending on the ULK material, a preparation anneal can be provided if the temperature is low enough to prevent from layer damage.

The three solvents were also tested on three parts of a same PECVD wafer (Fig. 3). We achieved an open porosity of $28.0 \pm 0.5 \%$ and a mean pore radius of 1.60 $\pm 0.25 \mathrm{~nm}$. These small discrepancies may come from the non uniformity of the wafer but also from the chemical nature of the solvents that may not interact in the same way with the ULK (polarity of methanol).

An organic contamination analysis was performed by Thermal Desorption Gas Chromatography Mass Spectrometry (TDGCMS) to assess the impact of solvents on the porous materials. A dedicated $300 \mathrm{~mm}$ PECVD sample was deposited and separated into pieces just before the analysis. A first piece was used as sample blank. A second piece was introduced in the EP12 and cycled without solvent to reference the process. Then each sample was measured with a different solvent. The TDGCMS experiment consists in a two steps analysis. The wafer is first put into a desorption chamber heated at $350{ }^{\circ} \mathrm{C}$ where contaminant

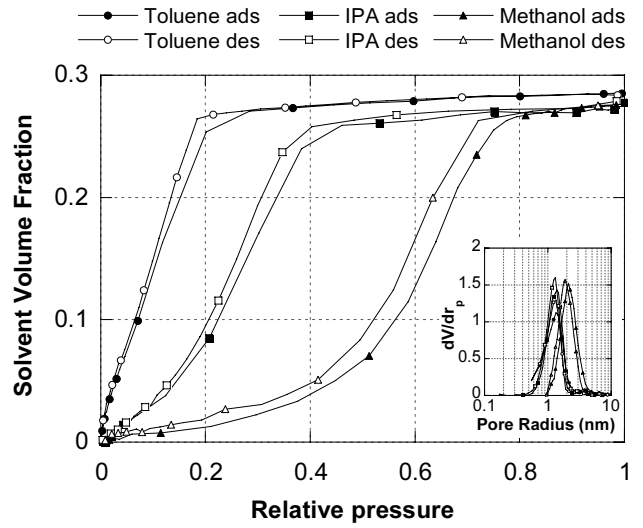

Figure 3 Solvent volumes and PSD of a PECVD ULK.

Table 1 Total organic contamination brought by EP measurement to PECVD samples.

\begin{tabular}{lcccc}
\hline & No solvent & Toluene & Methanol & IPA \\
\hline $\begin{array}{l}\text { Organic contamination } \\
\text { corrected from ULK }\end{array}$ & $0.23 \times 10^{+14}$ & $13 \times 10^{+14}$ & $6.6 \times 10^{+14}$ & $1.6 \times 10^{+14}$ \\
blank $\left(\right.$ atC $\left./ \mathrm{cm}^{2}\right)$ & & & & \\
Solvent purity & - & $99.5 \%$ & $99.8 \%$ & $99.9 \%$ \\
\hline
\end{tabular}

species desorb from both its front and back sides and are driven by an inert gas flow through a TENAX ${ }^{\circledR}$ sorbent trap maintained at $20^{\circ} \mathrm{C}$ for collection. During the second step, collected compounds are thermally desorbed from the TENAX ${ }^{\circledR}$ trap, and injected into a chromatographic column for separation. Then, the flow splits between a mass spectrometer for identification and a Flame Ionization Detector (FID) for accurate quantification. FID calibration is carried out in reference to the n-hexadecane response and a detection limit for individual compounds (200 $\mathrm{mm}$ wafers) of $\sim 10^{11}$ equivalent carbon atoms $/ \mathrm{cm}^{2}\left(\mathrm{atC} / \mathrm{cm}^{2}\right)$ is reached. As shown in Table 1, significant organic contaminants can be brought by the solvent during the EP run. The contamination is composed of low volatile molecules directly linked to residual species contained in the solvents. Indeed, this was confirmed by GCMS analysis of solvents impurities which correspond to the low volatile species detected on samples. Hence, the best solvent purity is needed to minimize the wafer contamination with low volatile species.

Monitoring the deposition process is important when integrating ULK to achieve the best physical properties (porosity, mechanical strength). Especially the UV curing process in the porogen approach is a key parameter. PECVD samples with different curing times were analysed with EP. As short curing times increase the open porosity induced by the evaporation of the sacrificial phase, longer curing times can affect the material and decrease the open porosity due to skeleton shrinkage (Fig. 4).

Another essential processing step is the ULK etching or stripping. The process has to be soft to prevent ULK 
damages that will make its dielectric properties worse. We monitored several plasma etchings performed on blanket wafers. Usually plasmas are modifying the ULK properties inducing a porosity loss or the apparition of a modified surface layer. On a spin-on sample we observed a loss of $11 \%$ porosity and the apparition of a hysteresis between the toluene adsorption and desorption curves that can be
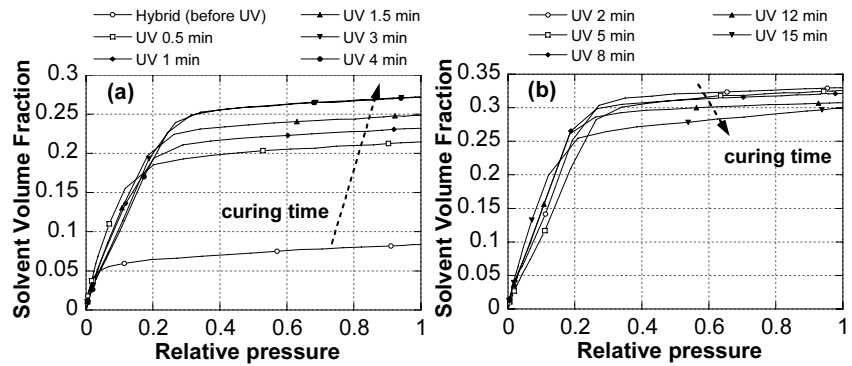

Figure 4 Solvent volumes vs. short (a) and long (b) curing time.

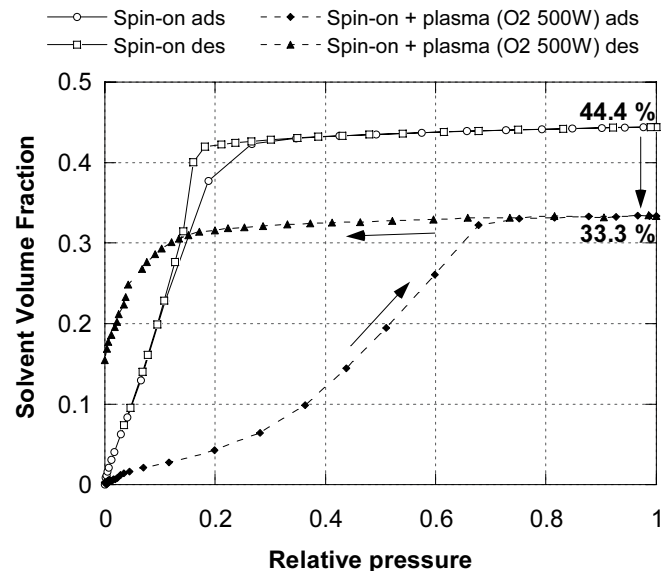

Figure 5 Effect of a plasma treatment on a spin-on sample.

attributed to the presence of an inhomogeneous barrier layer (Fig. 5) [11]. Indeed, as the measurements are dynamically performed during the pressure ramp up and ramp down, the presence of a barrier can induce a filling and emptying delay. The horizontal plateau of the curves after $P_{r e l}=0.7$ ensures that all open pores are filled. At the end of the cycle the refractive index of the plasma processed sample is higher than its starting value showing that solvent is still present in the layer. In this case a $200{ }^{\circ} \mathrm{C}$ anneal was mandatory to restore the layer as an extended vacuum pumping was ineffective.

Finally ULK materials need to be sealed in order to prevent the metal diffusion from the interconnect line which leads to a degradation of the dielectric properties. We achieved EP measurements on different sealing treatments on both blanket and patterned wafers using toluene and methanol as solvents. As the methanol molecule is $30 \%$ smaller than toluene the more severe sealing test is obtained with methanol. We showed that methanol can detect some porosity whereas toluene is not penetrating the layer (Fig. 6). However depending on the material that the
ULK needs to be isolated from, one has to choose the more representative solvent to check the sealing.

Multilayer ellipsometric models cannot be applied on patterned wafers, however we can check the sealing efficiency by monitoring the ellipsometric angles $\Psi$ or $\Delta$.

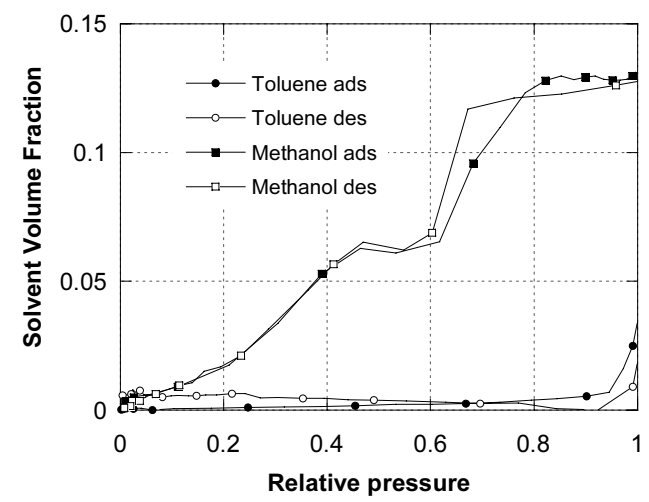

Figure 6 Solvent influence on a sealed ULK.
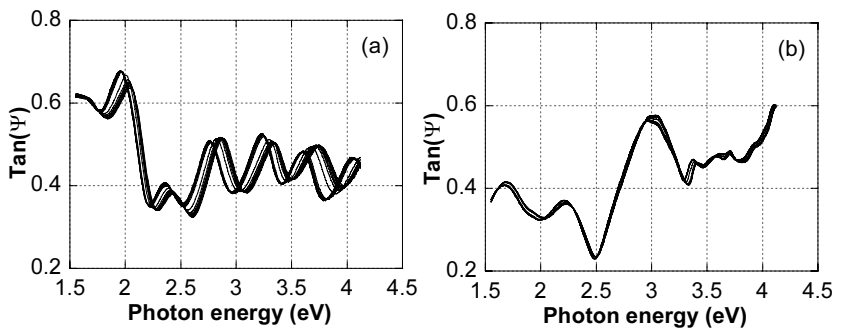

Figure 7 Porous (a) and sealed (b) patterned wafers responses.

Indeed the spectra of porous patterns are varying during the adsorption and desorption cycles due to refractive index variations, whereas the spectra of sealed patterns remain unchanged (Fig. 7).

4 Conclusion The Ellipsometric Porosimetry technology has demonstrated its interest and possibility to characterize ULK materials and above all to monitor their integration processes (deposition, curing, etching, stripping and cleaning). However the use of EP may be limited to "off-line" application due to the relatively long cycle measurement (typically 2 wafers per hour) and the possible contamination with organic species.

Acknowledgements Part of this work was supported by the MEDEA+ HYMNE project. The authors are grateful to SOPRA for the continuous and helpful support.

\section{References}

[1] http://public.itrs.net/.

[2] D. W. Gidley, W. E. Frieze, T. L. Dull, J. Sun, A. F. Yee, C. V. Nguyen, and D. Y. Yoon, Appl. Phys. Lett. 76, 1282 (2000). 
[3] M. P. Petkov, M. H. Weber, K. G. Lynn, K. P. Rodbell, and S. A. Cohen, Appl. Phys. Lett. 74, 2146 (1999).

[4] S. Kawamura, K. Maekawa, T. Ohta, K. Omote, R. Suzuki, T. Ohdaira, M. Tachibana, and K. Suzuki, in: Proceedings of the International Interconnect Technology Conference, Burlingame, USA, 2001, pp. 195-197.

[5] M. R. Baklanov, K. P. Mogilnikov, V. G. Polovinkin, and F. N. Dultsev, J. Vac. Sci. Technol. B 18, 1385 (2000).

[6] C. Wongmanerod, S. Zangooie, and H. Arwin, Appl. Surf. Sci. 172, 117 (2001).

[7] P. Revol, D. Perret, F. Bertin, F. Fusalba, V. Rouessac, A. Chabli, G. Passemard, and A. Ayral, J. Porous Mater. 12, $113(2005)$

[8] S. Nakao, J. Ushio, T. Ohno, T. Hamada, Y. Kamigaki, M. Kato, K. Yoneda, S.Kondo, and N. Kobayashi, in: Proceedings of the International Interconnect Technology Conference, San Francisco, USA, 2006, pp. 66-68.

[9] A. Bourgeois, A. Brunet Bruneau, S. Fisson, B. Demarets, D. Grosso, F. Cagnol, C. Sanchez, and J. Rivory, Thin Solid Films 447/448, 46 (2004).

[10] A. W. Adamson, and A. P. Gast, Physical Chemistry of Surfaces (John Wiley \& Sons, New York, 1997), p. 54.

[11] D. Shamiryan, M. R. Baklanov, and K. Maex, J. Vac. Sci. Technol. B 21, 220 (2003). 